\title{
Design, Implementation and Assessment of Videoconferencing Sessions in Earth and Life Sciences: The Case of the Agricultural University of Athens
}

\author{
Papadopoulos G. ${ }^{1}$, Voulagri I. ${ }^{2}$
}

\section{N F O \\ Received 16 Sept. 2010 \\ Accepted 10 Dec. 2010 \\ Available on-line 3 Apr. 2013 \\ Responsible Editor: A. B. \\ Sideridis}

\section{Keywords:}

video conferencing, higher education, agricultural studies, earth and life science, blendedlearning.

\begin{abstract}
A B S T R A C T
In this paper we present the methodology employed in the Agricultural University of Athens for the delivery of specific courses with the use of video conferencing technology. Earth and Life Science higher education courses (agricultural, environmental and biomedical courses) present specific requirements relevant to the exposure of the students to practical issues, and the exchange of expertise. The employment of video conferencing seems be a valuable solution for addressing a number of these requirements. We describe these requirements as they emerged from our study, and present the implementation of video conferencing sessions (design, application, and assessment). Through this paper we aim at describing examples of meaningful employment of video conferencing, particularly in higher education, share the positive and negative aspects of our approach, and provide insights for similar interventions in education and training.
\end{abstract}

\section{Introduction}

Research over the past decades indicates the potential and opportunities provided by videoconferencing (VC) as an educational tool (Amento and Brooks, 1998; Burge, 1994; Isaacs and Tang, 1994; Kaye, 1987; Locatis et al., 2006; Smyth, 2005; Bonk and Graham, 2006) and more specifically for demanding teaching environments such as the case of Earth and Life Sciences courses. In Earth and Life Science courses -agricultural, environmental and biomedical courses- teaching and learning conditions and requirements present certain peculiarities such as the necessity for connection with external, remote, rural locations, greenhouses, animal units, demonstrations of rare or unique events, simultaneous practical exercises of a large number of students in constrained laboratories and contact with research institutions and other relevant facilities. Videoconferencing in this context seems to provide solutions to setbacks and obstacles emerging from these peculiarities and also enhances and offers new potential to instruction, learning and hands-on experience of the students. It fosters cooperation and collaboration among remote participants and remote institutions; it may support students in remote areas where access of experts or access to specialized activities is difficult; it can be the only solution in cases where access to specific events or locations is impossible or hazardous or in cases where complex objects or procedures have to be demonstrated in detail to remote participants (Neale et al.., 1998) and it offers the opportunity to interact with experts from around the world cost and time effectively. It appears to be a solution in the cases where increased interaction among the participants is expected or required as, in relation to other forms of remote communication and Computer Mediated Communication (e.g. email, chat, fora) it provides the possibility for visual contact which creates a sense of social presence and consequently a more comfortable learning environment (Mason, 1994) as well as it permits a more direct and timely interaction among the participants.

The opportunity to integrate $\mathrm{VC}$ in the instruction process was presented for the Agricultural University of Athens (AUA) with the project "Implementation and Integration of New Technologies

\footnotetext{
${ }^{1}$ PAPADOPOULOS, George

Laboratory of Mathematics and Statistics, Agricultural University of Athens, 75 lera Odos Str., 11855, Greece gpapadop@aua.gr

${ }^{2}$ VOULGARI, Iro
}

Department of Educational Sciences and Early Childhood Education, University of Patras, 265 00, Greece avoulgari@upatras.gr 
in Education” for the Greek Universities, funded by the Greek Ministry of Education and the European Union. During this project (September 2006-December 2007) the AUA project team designed and implemented a number of VC sessions for the support and enhancement of the education and research activities. The potential benefits of videoconferencing as a tool for teaching and learning in higher education were the initial motivation for the participation of AUA in this project, as well as the limited research in the area of distance education and VC, more specifically in the case of agriculture and life sciences education.

Research in the area of distance learning in agriculture education has mainly focused on the delivery of distance courses to off-campus students, as well as on the effectiveness of distance education in the learning process, in relation to conventional methods of instruction (Miller, 1997; Gray and Miller, 1999; Miller and Pilcher, 1999; Bowen and Thomson, 1995; Irani et al., 2000). Our viewpoint to the subject, though, was founded on a different perspective: the main goal of the project was to integrate distance learning tools and methodologies, and VC more specifically, in order to support and enhance on-campus instruction for on-site students considering the potential of the technology in relation to existing needs and requirements of courses taught at the Agricultural University, both concerning the instructors as well as the material, the educational objectives and the hands-on experience to be attained by the students. A blended-learning approach was adopted, with the instructors, the students, the material and/or activities and the available technology as the main defining factors for the implementation of VC.

During the project, twenty two (22) VC session scenarios were designed, with the participation of faculty members and 8 of them took place during the spring and the winter semester of 2007. In section 2 we present a brief description of the methodology for the design of the scenarios. In section 3 the implementation methodology is detailed and section 4 refers to the assessment and results of the implemented sessions by the participants. In section 5 the general conclusions that can be drawn for similar cases of Earth and Life Sciences courses are discussed.

\section{Designing Scenarios}

The design of the scenarios may be considered as one of the most critical steps for the successful implementation of VC sessions. Instruction with the use of VC requires a more detailed planning than the conventional methods of instruction, as well as the re-organisation and re-design of the content and educational approach, so as for the potential and dynamic of VC to be fully exploited (Kaye, 1987; Garrisson, 1989). A number of defining factors were addressed during the design phase. These factors were the synchronous and asynchronous interaction and communication among the participants, the number of points and of participants, the motivation of the students, turn-taking by students or speakers, the balanced cooperation and participation of all participating points, the quality of the educational content, and the technical support available.

After an initial phase of dissemination of the objectives of the project to the AUA academic community, a number of training seminars and day-events for updating the faculty members of the available VC resources and equipment as well as for motivating them to consider integrating VC into their teaching, a base of instructors interested in employing VC emerged. The Design Team of the project cooperated closely with these instructors for recording and mapping the particular conditions and requirements of instruction in AUA and for designing specific scenarios customised to their needs and requirements. A general template scenario was developed, for facilitating the design of new scenarios in AUA. The structure of this template is presented in Table 1. 
Table 1. Template used for the development of the educational scenarios

\begin{tabular}{|c|c|}
\hline Required Field & Description \\
\hline $\begin{array}{l}\text { Designated faculty } \\
\text { member }\end{array}$ & The name of the tutor responsible for the VC session \\
\hline Date & The time/date of the implementation of the session \\
\hline Type of use & $\begin{array}{l}\text { The model of videoconference (lecture/tutorial, seminar, presentation, } \\
\text { collaboration between researchers, demonstration of experiment or process, } \\
\text { debate) }\end{array}$ \\
\hline VC type & Point to point or multi-point connection \\
\hline Sites & The sites which will be connected during the VC session \\
\hline Target group & $\begin{array}{l}\text { The group the VC session is targeted to (students undergraduate or/and } \\
\text { postgraduate-,university staff, researchers, public audience etc) }\end{array}$ \\
\hline Duration & The duration of the session \\
\hline Brief description & Brief description of the session (e.g. content, purpose, objectives) \\
\hline Why VC & $\begin{array}{l}\text { Justifies the need of VC and the added value compared to traditional teaching } \\
\text { methods. Describes how VC will improve the quality of the course. }\end{array}$ \\
\hline $\begin{array}{l}\text { Integration in the } \\
\text { curriculum }\end{array}$ & The course or the courses in which the session is integrated. \\
\hline $\begin{array}{l}\text { Instructional } \\
\text { objectives }\end{array}$ & The educational/instructional objectives of the VC teaching session. \\
\hline Participants & Number and the roles of the participants \\
\hline Preparation & Outline of the preparation which should take place before the VC session \\
\hline $\begin{array}{l}\text { Educational } \\
\text { /support material }\end{array}$ & $\begin{array}{l}\text { Describe the type of the educational or other material used during the session. } \\
\text { Description of additional technical equipment required during the session. }\end{array}$ \\
\hline $\begin{array}{l}\text { Detailed } \\
\text { description }\end{array}$ & $\begin{array}{l}\text { The whole session is described in detail (actions of the tutors, type and } \\
\text { duration of the activities, presentations, interaction and discussion) }\end{array}$ \\
\hline $\begin{array}{l}\text { Further } \\
\text { exploitation of } \\
\text { results }\end{array}$ & $\begin{array}{l}\text { Methods of further exploitation and reuse of the material and equipment (e.g. } \\
\text { video recorded, educational material, scenarios) are proposed in this field }\end{array}$ \\
\hline Technical context & The technology used and the additional equipment which might be needed \\
\hline $\begin{array}{l}\text { Evaluation } \\
\text { comments }\end{array}$ & $\begin{array}{l}\text { An evaluation of the whole VC session, the informal feedback and the } \\
\text { experience acquired (field completed after the VC session). }\end{array}$ \\
\hline
\end{tabular}




\subsection{Instructional Design Principles}

The main objective of the design of the educational scenarios was the detailed planning and organisation of the educational content and of the relevant instructional methods so as to fully benefit from the session and exploit the potential of the technology considering the instructional objectives of the course. A crucial point was the legitimacy of the integration of videoconferencing in a class. VC sessions were only implemented in the cases where it would in fact be the best solution possible for coping with any problems or for enhancing and improving the quality of the course. The scenarios that were designed as well as the VC sessions that took place, demonstrate the necessity of VC sessions for specific courses in AUA; courses with needs that go beyond the level of communication and collaboration among remote participants, as would be the case in other higher education institutions. In these cases, VC seems to provide a solution to real practical and logistical problems, such as visits to remote or restricted areas, demonstrations of experiments which would otherwise be difficult or impossible, that have been constraining the quality of the courses and have been limiting the instructional objectives. It is obviously not suggested that videoconferencing should substitute the experience of the direct contact (Bonk and Graham, 2006). For more details on the planning and design of the scenarios and the sessions see also Sideridis et al. (2007).

\subsection{Mapping the Instructional Settings in AUA in Relation to Videoconferencing Use}

The AUA focuses on agricultural sciences, teaching and basic and applied research. It is situated in a 25-hectare green campus equipped, among others, with auditoriums, laboratories, agricultural facilities -such as an arboretum, a vineyard, laboratories, a flower garden, greenhouses, a cowshed, a sheep pen, a chicken coop, dairy installations, and aquaculture tanks. Furthermore, a number of farms located outside the campus and in remote areas around Greece are in the possession of the University, all targeted to serve the instructional and research needs of AUA. Instruction during the first nine semesters includes lectures, laboratory work and field trips. Four months of practical training are also required to ensure familiarization with actual farm conditions. Teaching conditions in AUA seem therefore to provide a significant opportunity for exploiting the potential of VC.

While investigating the conditions of instruction in AUA and mapping the needs emerging where VC could be the most efficient or even the only possible approach, a number of particular cases where recorded. Indicatively (for more details see also Sideridis et al., 2007): a) connection of classes with external locations such as fields, units for production, hydroponics laboratories, animal production units, greenhouses and research institutions, where detailed presentation of locations, and clarification of processes and features of livestock and vegetation are required, b) presentation of research activities and interaction with remote experts and specialists, c) demonstrations to the students from anatomy laboratories or microscopes, where the large number of students or the small-sized laboratories constraint attendance, d) connection of the class with beehives for Apiculture courses, where physical presence of students is not always possible (e.g. due to allergies or hostile behaviour of bees), e) cases or events that require the direct, timely and accurate scientific communication with other members of the academic community, the media and even the public, f) cooperation and interaction of AUA with other university departments and specialists from other universities, g) lectures to AUA classes by remote experts, or h) lectures from AUA to remote or isolated students, and i) presentation of research activities of students, to other universities or remote supervisors.

Based on the aforementioned framework, the instructional settings mapped and the emerging needs, the Design Team developed 22 customized educational scenarios, which correspond to almost all the categories of uses of VC in higher education, such as Lectures/ tutorials, seminars, presentations, collaboration between researchers, while cooperating closely with the Technical Team of the University so as to ensure the availability of the technical equipment in order to realize these scenarios. Additional equipment was purchased by AUA such as specialized cameras for the microscopes, and mobile units for the connection of the videoconferencing rooms with external locations. 


\subsection{Implementation Methodology}

The Design Team was responsible for the implementation of the scenarios. The members of the team were familiar with the factors concerning the successful realisation of the sessions, and had relevant previous experience in Educational Technology and VC implementation. Each member of the team was responsible for a specific number of sessions (2-3 sessions). The person responsible for each session would coordinate all the participating members (i.e. lecturers, technicians, VC room attendants) for the most efficient preparation possible. Such preparation activities include the following: arrange the date and time, availability and booking of the VC rooms, technical trials, preparation of the educational material, timely notification of the participants, guidelines on the direction and familiarisation of the participants with the equipment. The Design Team was present in the VC room during the session so as to assist in the case of any problems, to ensure a sense of confidence from the part of the lecturers, as well as for recording and keeping notes on the process. Assessment of the VC sessions (i.e. preparation, distribution and collection of questionnaires) was also among the responsibilities of the Design Team.

Based on the aforementioned implementation methodology, 8 VC sessions were realized: 3 session scenarios were classified as "lecture/tutorial", 2 aimed at the "collaboration between researchers" and 1 scenario -which was the basis for 3 sessions- was classified as a "seminar". In relation to the number of participating sites (connection points), 7 VC sessions were "point to point" and one required a "multi point" connection: in two cases the AUA VC room was connected with a laboratory within the campus and with an external location respectively. For the remaining six sessions the AUA VC room was connected with the VC rooms of the other participating remote sites (Figures 1 and 2). In Table 2 the implemented sessions are summarized (see more details on the implementation of the VC sessions in Papadopoulos et al., 2008). 


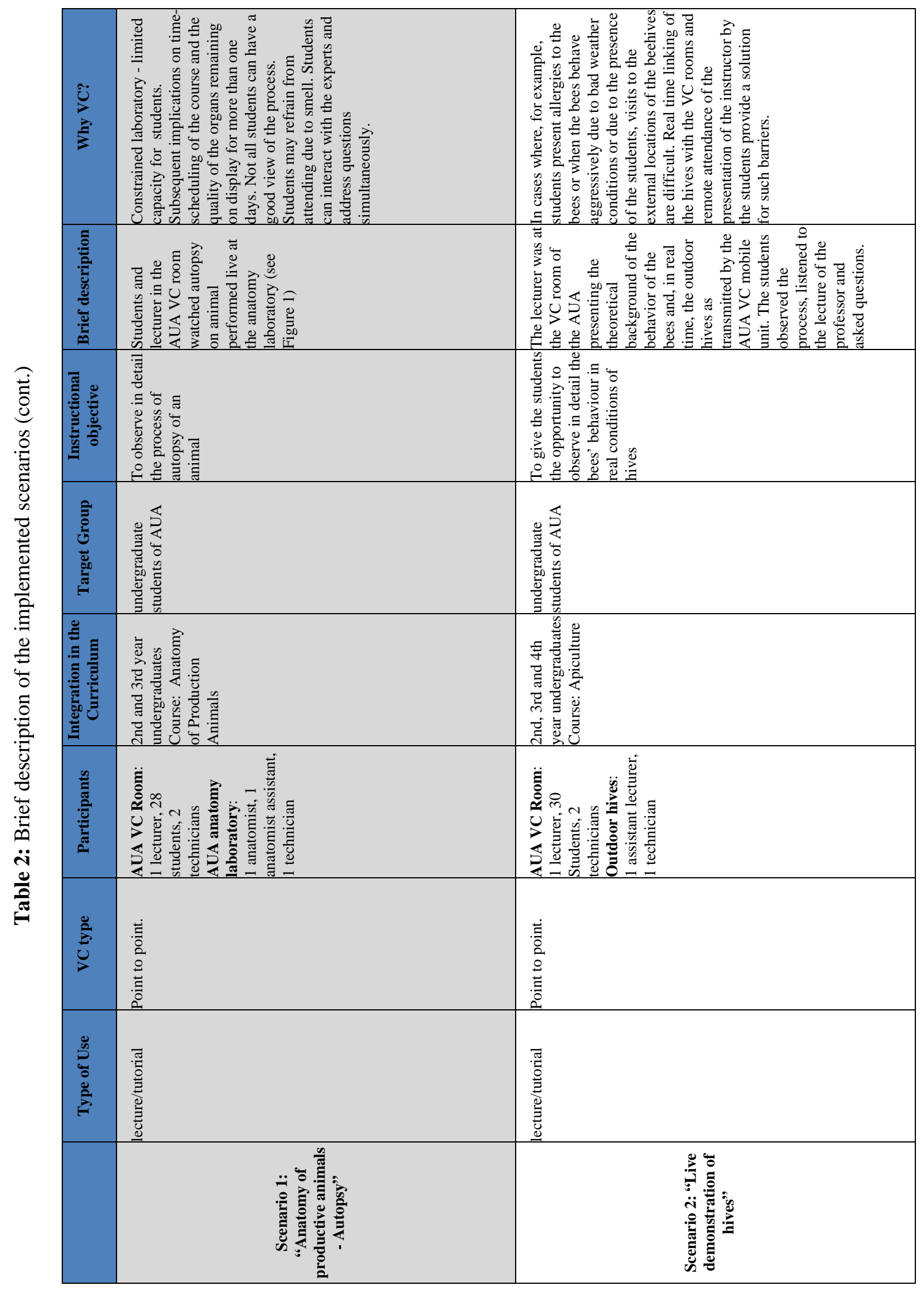




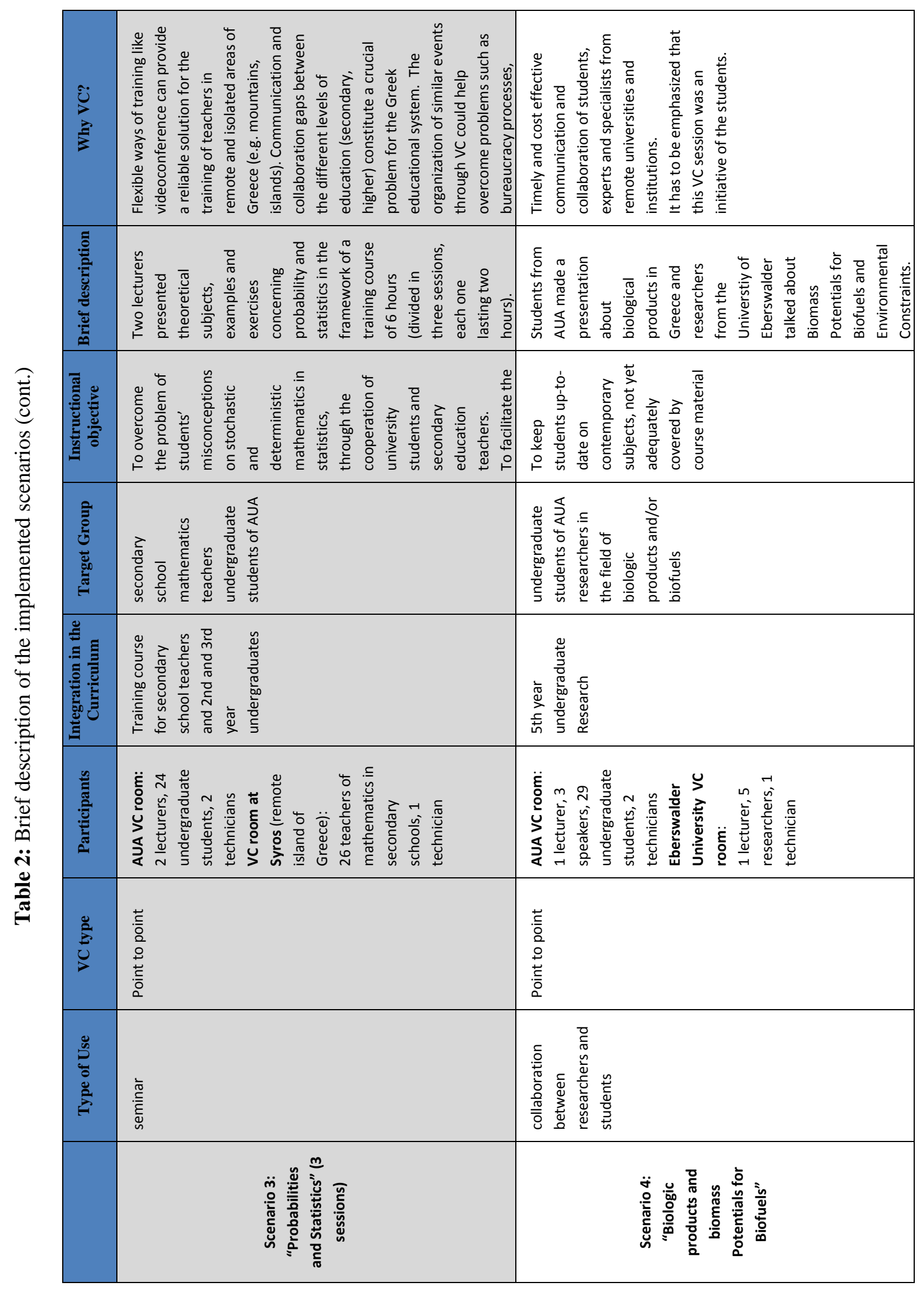




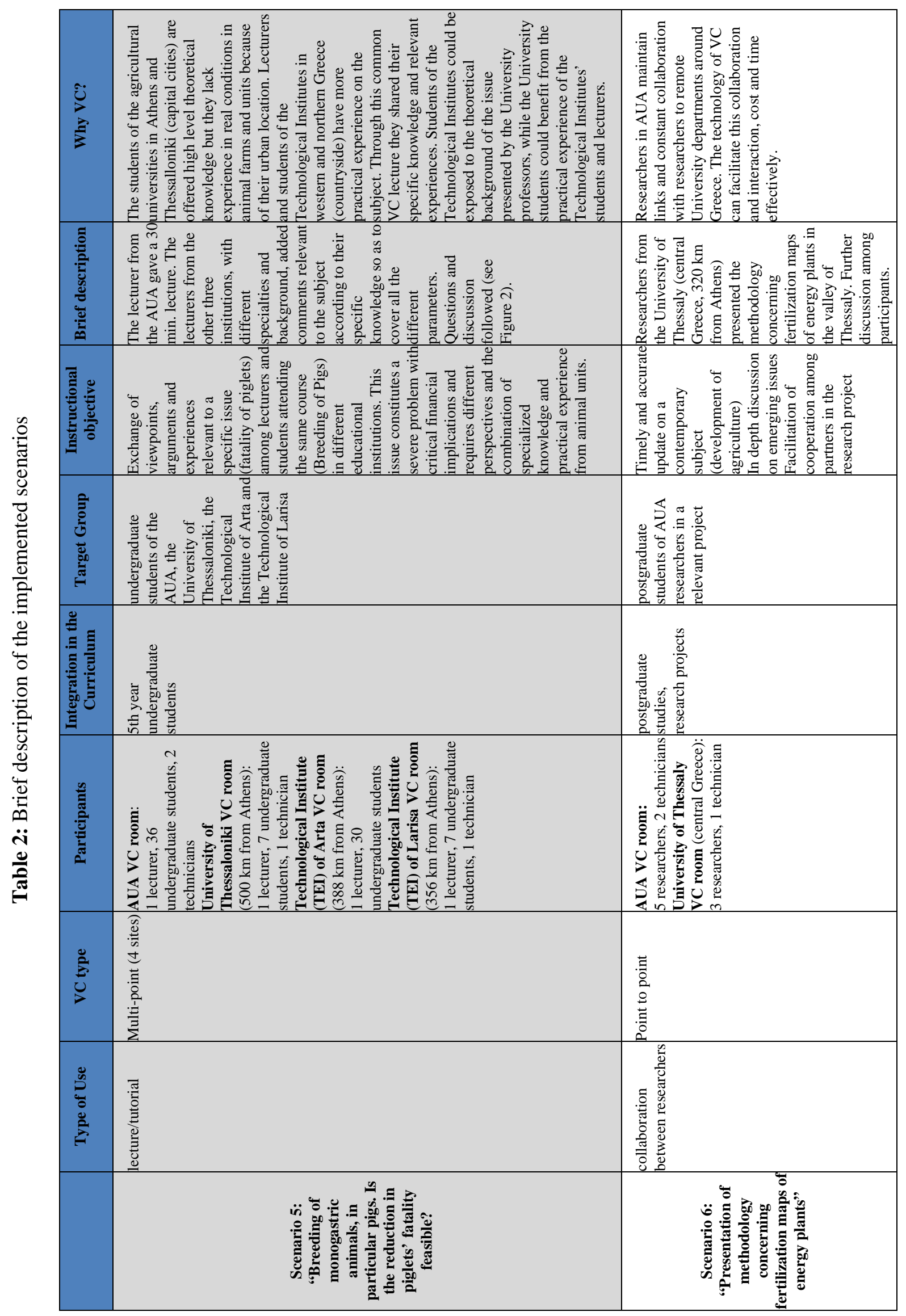



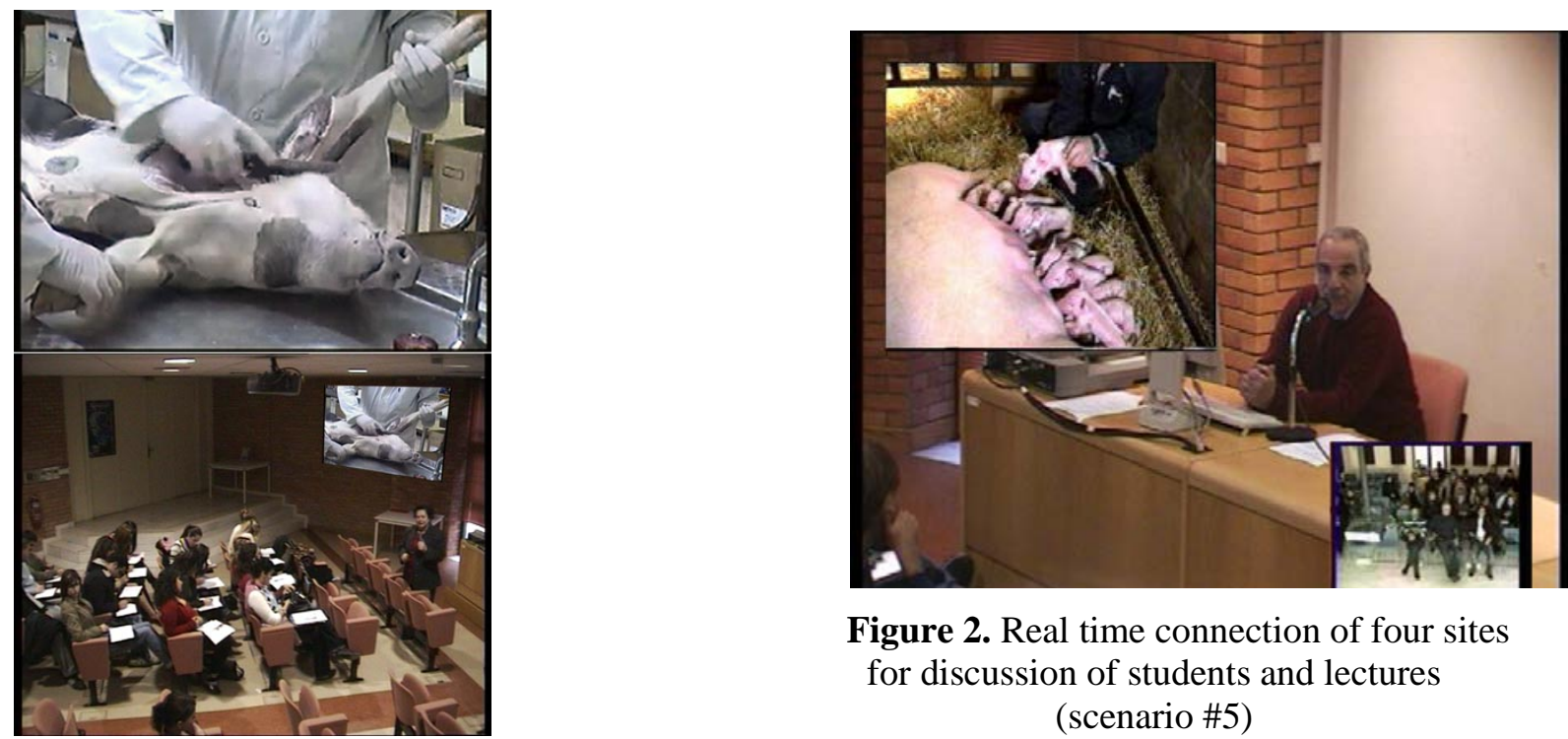

Figure 2. Real time connection of four sites for discussion of students and lectures (scenario \#5)

Figure 1. Real time connection of the AUA $\mathrm{VC}$ room with the AUA Anatomy Laboratory (scenario \#1)

\section{Assessment and Results}

\subsection{Assessment Methodology}

The objectives of the assessment were a) the investigation of the opinions, perceptions and attitudes of the participants for the particular sessions as well as for VC in education in general, after their experience with VC and b) to provide the possibility to the participants to express their proposals and suggestions. For the assessment a survey was employed. Two different questionnaires were constructed: for students and for lecturers.

The questionnaires were distributed to the participants, on site, after the completion of the session. They were anonymous and consisted of 8 closed ended questions (yes-no) and 2 open ended questions for further comments by the participants. In this study we will mainly focus on the feedback from the students. The students' questionnaire is presented in Table 3. 
Table 3. Questionnaire for the students

\begin{tabular}{|l|l|}
\hline No. & Question \\
\hline Q1 & Did you find the VC session you just attended interesting? \\
\hline Q3 & Would you be willing to attend more classes via VC? \\
\hline Q4 & $\begin{array}{l}\text { Would you rather the lecture had been conducted with conventional teaching } \\
\text { methods? }\end{array}$ \\
\hline Q5 & $\begin{array}{l}\text { During the VC session, did you have any questions you did not have the } \\
\text { opportunity to ask? }\end{array}$ \\
\hline Q6 & $\begin{array}{l}\text { Would you like to have access, via the web, to material relevant to the VC } \\
\text { session AFFORE the session? }\end{array}$ \\
\hline Q7 & $\begin{array}{l}\text { Would you like to be able to comment on the content of the VC session and } \\
\text { discuss it with your peers and teachers, online (e.g. via a forum)? }\end{array}$ \\
\hline Q9 & \begin{tabular}{l} 
What do you consider to be the positive points of the current VC session? \\
\hline What do you consider to be the weak points of the current VC session?
\end{tabular} \\
\hline
\end{tabular}

227 students' questionnaires (191 AUA students, 26 secondary education teachers, 10 postgraduate students and researchers) and 10 lecturers' questionnaires were fully completed and returned. Although all the questionnaires were reviewed, in the current study, the 191 questionnaires from the AUA students were analysed.

Furthermore, the Design Team was attending the sessions and recording field notes relevant to any specific events, and the behaviour and actions of the participants.

\subsection{Results}

The following results refer to the responses of the 191 AUA students who participated in the VC sessions realised during our project. The statistical analysis included tests for comparison of proportions. For the statistical analysis the package STATGRAPHICS Plus v.4 (Statistical Graphics Corp.) was used.

In Figure 3 the observed proportion for each of the 5 scenarios, per question, is shown. The mean proportion (pooled) and the 95\% decision limits is also shown. Since none of the samples falls outside the decision limits, there was no significant difference among them, for each question. 


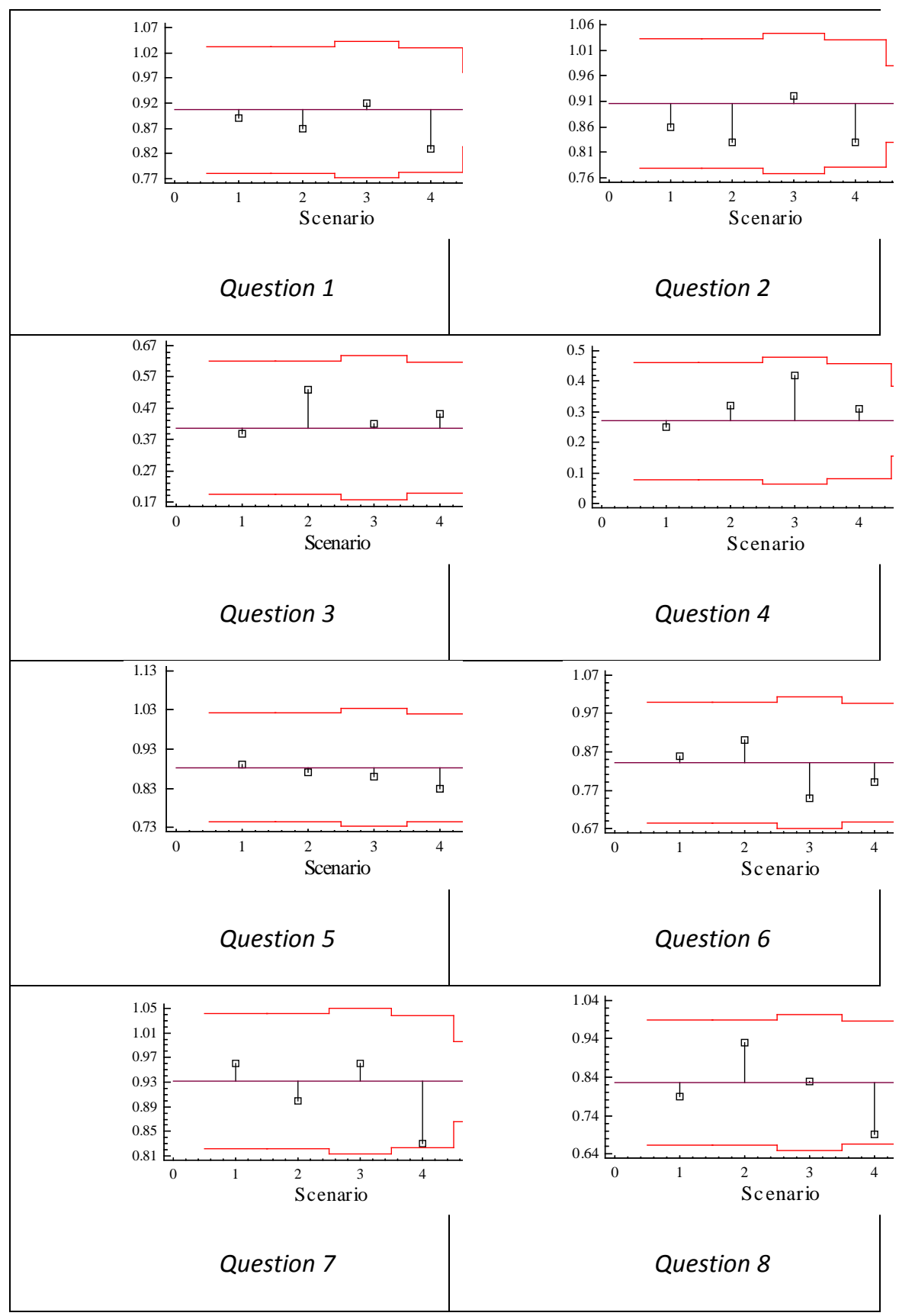

Figure 3. Analysis of Means Plot with 95\% Decision Limits

More specifically, according to the students $(\mathrm{N}=191)$ : a) the sessions were interesting, at high proportions (range from 0.83 to 0.95 ) with mean (pooled) proportion 0.91 . There were no significant differences between the sessions ( $\mathrm{p}=0.3555)$. $\mathrm{b}$ ) They would be willing to attend similar sessions in the future, at high proportions (range from 0.83 to 0.97 ) with mean proportion 0.9. There were no significant differences between the sessions $(\mathrm{p}=0.0782)$. c) The quality of the image and sound was not assessed as satisfactory indicated by the low levels of satisfaction (range from 0.35 to 0.53 ) with mean proportion 0.41 . There were no significant differences between the sessions ( $p=0.5404)$. $d)$ The participants do not seem to prefer conventional teaching methods over VC at the particular lessons (range from 0.2 to 0.42 ) with mean proportion 0.27 . There were no significant differences between the sessions ( $\mathrm{p}=0.2509$ ). e) The participants reported that they felt they had the opportunity to express any questions they had during the sessions, at high proportions (range from 0.83 to 0.91 ) with mean proportion 0.88 . There were no significant differences between the sessions $(p=0.8215)$. $f)$ They expressed their requirement to have access to educational material before the realisation of the session, 
at high proportions (range from 0.75 to 0.9 ) with mean proportion 0.84 . There were no significant differences between the sessions $(\mathrm{p}=0.5455)$. g) The participants also expressed their requirement to have access to educational material after the session, at high proportions (range from 0.83 to 0.96 ) with mean proportion 0.93 . There were no significant differences between the sessions $(\mathrm{p}=0.1487)$. $\mathrm{h})$ The participants want to be able to comment and discuss on the particular session with lecturers and peers, at high proportions (range from 0.69 to 0.93 ) with mean proportion 0.83 . There were no significant differences between the sessions $(\mathrm{p}=0.1705)$. i) There were no significant differences between on-site and off-site participating students (alpha $=0.05$ for all questions). Off-site students non AUA students- were available only in Scenario \#5.

The proportions of positive answers (yes) in Q6 and Q7 were high, even though, access to relevant material before and after the sessions was not considered essential, as it emerged from the comments included by the students. Similar was the case in Q8 concerning the attitudes of the students in relation to the access to online fora.

The main strength of VC, as concluded by the answers of the students to the open ended Q9 is the potential for a more effective approach to knowledge and learning. The quality of the image and the audio was the main weakness as commented by the students in Q10. The results were similar in the case of secondary education teachers $(\mathrm{N}=26)$. Secondary education teachers participated only in session \#3.

For the researchers and lecturers, no statistical analysis was conducted, due to the small size of the sample $(\mathrm{N}=10)$. However their answers to the questionnaires show a high degree of satisfaction from the implemented VC sessions and a tendency to participate again in similar activities. They would also recommend VC sessions to other colleagues and they commented that they attained educational objectives that they would not attain with other methods.

\subsection{Discussion}

As indicated by the analysis and the observations and field notes of the Design Team, although a number of critical issues which can potentially affect the quality of a VC session emerged, there was a general positive attitude from the part of the participants.

The students were particularly critical towards the technical problems that appeared and the quality of the image and the audio. This may be attributed to the familiarisation of the students with high quality technology products and therefore having high expectations. Even though the proportions of satisfaction by the quality of the image and audio (Q3) were low, the corresponding proportions of satisfaction by the sessions (Q1) and the intention to attend similar sessions again in the future (Q2) were quite high. Furthermore, the proportions of preference to conventional methods and not VC for the specific scenarios realised (Q4) were low.

The case of a particular session (Scenario \#5) is worth highlighting, where although extended technical problems were presented (the lowest proportion of positive answers in Q3), the students were not negatively affected and expressed their interest and their intention to attend similar VC sessions in the future (the highest proportions in positive answers for Q1 and Q2) and their preference of VC sessions over conventional teaching methods for the particular lesson (the lowest proportions of positive answers in Q4). This may be explained by the fact that the particular scenario capitalised, at a high degree, the comparative advantages of VC technology. In this session the students had the opportunity to attend the lectures and viewpoints of four different professors on a particular, multidimensional subject.

The proportions of students who preferred conventional instructional methods rather than the use of VC sessions were low. The highest proportion of this tendency was observed in scenario \#3, where the students were attending the presentation of their lecturer at the VC room of their university (AUA), with no other lecturer at the remote site. A student commented, indicatively: "I didn't attend a videoconference lecture but a lecture". On the other hand, for the same session, the participants at the remote site (secondary education teachers) declared, in a very high proportion, that they preferred the VC session. One of the remote participants commented: "I had the impression that I was in a 
University amphitheatre, attending a brilliant lecture”. Therefore it is crucial, while designing the scenarios, that the connection of the remote sites is meaningful for all the participants.

The students indicated their interest in accessing online material before and after the session, as well as in participating in online conversations relevant to the courses, with peers and lectures, indicating the motivation for interaction triggered by such VC sessions.

Despite the positive attitudes and interest for the VC sessions, the students did not seem to interact as much as expected with the on-site lecturer and the off-site participants. It seems that the distance factor is difficult to bridge, despite the potential provided by the technology. The problem was accentuated by the presence of technical problems in image and sound quality (e.g. clarity of the image), directorial decisions (e.g. lack of close-ups of the speakers), and extended monologues from the part of the speakers. For example, in the case of Scenario \#5, despite the technical problems, the interaction and participation of students and lecturers was higher, as the speaker would interrupt the lecture and invite questions and comments from the participants, on-site and remote. The case of scenario \#3 was quite different: although the students expressed their enthusiasm for the lectures, their participation with questions and comments was limited. In this case, the lectures were relatively long in duration. Another important factor, which seemed to affect the participation and interaction of the students, was the factor of the "unknown audience". Specific techniques are, therefore, required, such as large screens, close-ups to the participants, introduction of the participants before the sessions (e.g. through exchange of photographs and CVs). Specific details have also to be considered for a more successful interaction, such as the language of communication. As an example, we cite the case of scenario \#4, where the poor English language skills of the remote lecturer and of some of the students limited the quality of the interaction.

As indicated by the statistical analysis, there were no significant differences among sessions for all the questions, even though the types, objectives, participants and lecturers for each scenario were different. This may be attributed to the fact that all the scenarios and sessions were responding to actual educational needs.

For a successful VC session, certain details appear to be of critical importance, such as the technical trials that have to be realised in similar to the actual sessions' conditions. Indicatively, although during the trials of scenario \#4 no problems were presented, during the actual session severe technical problems caused by the bandwidth overload, limited the quality of the session. This was attributed to the time of the day the actual session took place.

\section{Conclusions}

As indicated by our experience in this project, the teaching and learning processes in Earth and Life Science courses present a wide range of challenges and requirements which constitute valuable opportunities for the effective implementation of VC sessions. The detailed and in-depth design of the appropriate VC scenarios and the instructional design are crucial factors for the success of the sessions (Lim et al.., 2012). For the implementation of VC sessions, the educators will have to be involved in an instructionally and technologically complex environment, with a wide range of factors to be considered. It is, therefore, essential that the appropriate scenarios address specific educational objectives and actual teaching and learning needs.

Furthermore, a different teaching approach is required from the part of the lecturers: the sessions have to be more interactive for all the participating sites, both local and remote. The control of all the parameters affecting the active involvement and the interaction among the participants is essential. Interventions, which might seem trivial, such as directorial or technical decisions, if not appropriately considered, are likely to undermine the particular approach and lead to additional problems and unnecessary educational "noise".

The VC sessions can motivate interaction among participants, prior and after the session. This potential could be further harnessed by the development of supporting environments (e.g. a relevant website with fora for the online interaction of participants). The active participation and the interaction of the students with the material and with peers constitute an important factor for the effectiveness of 
the teaching and learning processes (for similar findings regarding the preference of students for interaction with the content and with instructors and peers, see also Miller et al., 1999). Furthermore, such a supporting environment could address the issues of the "unknown audience", through the exchange of profiles and expertise. Participants who are already familiar with each other can more actively interact during the VC session.

Although the added value of meaningful VC sessions could mitigate the effect of possible technical failures, it is nevertheless necessary to eliminate through multiple technical trials and on-site support the technical features that may deteriorate the quality of the session and de-motivate the participants, both lecturers and students.

Although further research would be required for investigating weather the positive attitudes of the students were actually linked to the effectiveness of the employment of VC as an educational medium and not to the novelty of such a setting, the positive attitude of the lecturers and students cannot be disregarded. Positive attitudes of agriculture students towards video conferencing have also been identified in relevant studies (Meena et al., 2011). Furthermore, VC, in relation to other relevant technologies, emerged as a unique and valuable solution for addressing specific instructional needs and requirements. The experience of the VC sessions in AUA could possibly be relevant to the needs and requirements of other educational institutions with similar orientation.

\section{Acknowledgements}

This project was funded by the EU and the Ministry of Education of Greece. Special thanks are due to the Professors of AUA: A. B. Sideridis, A. Bouranis, S. Deligeorgis, P. Harizanis, H. Passam, S. Rozakis, E. Tzamos and E. Xylouri.

\section{References}

Amento, B.S. and P.C. Brooks. 1998. Making media spaces useful: video support and telepresence. Hypermedia Technical Report HCIL-98-01. Human-Computer Interaction Laboratory, Virginia Tech, Blacksburg, VA, USA.

Bonk, C. J. C. R. and Graham. 2006. The Handbook of Blended Learning: Global Perspectives, Local Designs. San Francisco: John Wiley and Sons.

Bowen, B. E. and J. S. Thomson. 1995. AG*SAT: An International Distance Education Alternative. Journal of Agricultural Education 36 (1), 15-23.

Burge, E.J. 1994. Learning in a computer conferenced contexts: The learners’ perspective. Journal of Distance Education, 9 (1), 19-43.

Garrison, D.R. 1989. Understanding Distance Education: A Framework for the Future. London: Routledge.

Gray, T. and W.W. Miller. 1999. Preferences and experiences of distance learners participating in agricultural distance education courses. In Proc. 26th National Agricultural Education Research Conference, 354-364.

Irani, T., C. Scherler, M. Harrington, and R. Telg. 2001. Overcoming barriers to learning in distance education: The effects of personality type and course perceptions on student performance. In Proc. 27th Annual National Agricultural Education Research Conference, 27, 434-448.

Isaacs, E. and J.C. Tang. 1994. What video can and cannot do for collaboration. Multimedia Systems, 2, 63-73.

Kaye, A. 1987. Computer conferencing and electronic mail. Open Learning for Adults, 186-193.

Lim, C., H. Kim, S. Kim, D. Kim and H. Lee. 2012. Development of instructional design model for collaborative videoconferencing. In Proc. World Conference on E-Learning in Corporate, Government, Healthcare, and Higher Education 2012 (pp. 1535-1540). Chesapeake, VA: AACE. T. Bastiaens \& G. Marks (Eds.).

Locatis, C., C. Gaines, W. L. Liew, M. Gill, J. Camey, J. Foster, V. McCall and M. Woods. 2006. A blended training approach using videoconferencing for distance education. Journal of the Medical Library Association, 94(4), 464-468.

Mason, R. 1994. Using communications media in open and flexible learning. Stylus Publishing, LLC.

Meena, M., K. Singh, H.Meena, M. Kanwat. 2011. Attitude: A determinant of agricultural graduates’ participation in videoconferencing technology. Journal of Agricultural Science, North America, 4. 
Miller, G. and C. Pilcher.1999. Desired and assessed cognitive levels of instruction: Are college of agriculture courses taught on campus and at a distance comparable? In Proc. 26th National Agricultural Education Research Conference, Gainesville, FL: American Association for Agricultural Education, 343-351.

Miller, G. 1997. Agricultural education at a distance: attitudes and perceptions of secondary teachers. Journal of Agricultural Education, 38(1), 54-60.

Neale, D.C., M.K. McGee, B.S. Amento P.C. and Brooks. 1998. Making media spaces useful: video support and telepresence. Hypermedia Technical Report HCIL-98-01. Human-Computer Interaction Laboratory, Virginia Tech, Blacksburg, VA, USA.

Papadopoulos, G., I. Voulgari, and E. Houssou. 2008. Implementation and assessment of videoconferencing sessions in earth and life sciences: the case of the Agricultural University of Athens. In Proc. World Conference on Educational Multimedia, Hypermedia \& Telecommunications, 793-802. Chesapeake, VA: AACE.

Sideridis, A. B., G. Papadopoulos, I. Voulgari, and E. Houssou. 2007. Design issues for videoconferencing in earth and life sciences: the case of the Agricultural University of Athens. In G. Richards (Ed.), In Proceedings of World Conference on E-Learning in Corporate, Government, Healthcare \& Higher Education, 1853-1860. Chesapeake, VA: AACE.

Smyth, R. 2005. Broadband videoconferencing as a tool for learner-centred distance learning in higher education. British Journal of Educational Technology, 36 (5), 805-820. 